\title{
Experimental investigation on the post-fire cyclic behavior of
} \section{grouted sleeve connections}

\author{
Tan Wang ${ }^{\mathrm{a}}$, Min Yu ${ }^{\mathrm{a}, \mathrm{c}, *}$, Xiangyu $\mathrm{Li}^{\mathrm{a}}$, Zegang Yan ${ }^{\mathrm{a}}$, Mohamed Saafi ${ }^{\mathrm{b}}$, Jianqiao Ye ${ }^{\mathrm{b}, *}$ \\ a. School of Civil Engineering, Wuhan University, Wuhan 430072, China; \\ b. Department of Engineering, Lancaster University, Lancaster, LA1 4YR. UK; \\ c. Engineering Research Center of Urban Disasters Prevention and Fire Rescue Technology of \\ Hubei Province, Wuhan 430072, China;
}

\begin{abstract}
Grouted sleeve connections have been widely used in precast construction for joining rebar. In order to study their post-fire seismic performance, grouted sleeve connections, which are heated first to elevated temperature and then cooled down to room temperature, are tested under both monotonic and cyclic loadings. For comparisons, the same tests are also carried out on continuous rebar. The failure modes, skeleton curves and compression strength of the specimens are analyzed to study the influence of temperature on the seismic performance of the grouted sleeve connections. The results show that buckling occurs to all the grouted sleeve connections under monotonic loading. It is also found that the skeleton curves, compressive and buckling strength of both the connections and the continuous rebar decrease with the increase of temperature up to $600^{\circ} \mathrm{C}$. From the test results and on the basis of the GMP and GA hysteric constitutive models of steel, a modified model for cyclic constitutive law of the continuous rebar and the grouted sleeve connections is presented and validated. The results demonstrate that the modified model is capable of accurately simulating hysteretic properties of steel rebars and grouted sleeve connections.
\end{abstract}

Keywords: grouted sleeve connections; elevated temperature; cyclic loading; seismic performance; constitutive model

\section{Introduction}

Grouted sleeve connections have been widely used in precast construction to join rebar for convenience and reliability. Many researchers have carried out numerous experimental studies to optimally design grouted sleeve connections, where the design parameters include grouting material ${ }^{[1]}$, geometry of sleeve $\mathrm{e}^{[2,3]}$, length of sleeve ${ }^{[4]}$, length of embedment ${ }^{[5]}$, size of rebar ${ }^{[6]}$ and rebar offset ${ }^{[7]}$. The results have shown that the strength of a grouted sleeve connection may be higher than that of a continuous rebar if it is properly designed. Zhao ${ }^{[8]}, \mathrm{Kim}^{[9]}, \mathrm{Lin}^{[10]}$, Zheng ${ }^{[11]}$ and $\mathrm{Xu}^{[12]}$ carried out experimental research to study the effect of cyclic loading on the mechanical performance of grouted sleeve connections. The results show that the bond strength degenerates after being loaded cyclically. The concrete cover is likely to crush under seismic action, leading to loss of protection and buckling of rebar. Many researchers studied seismic performance of precast structures with sleeves connections, including column-to-foundation connections ${ }^{[13-18]}$, beam-column connections ${ }^{[19,20]}$, column-to-column connections ${ }^{[21,22]}$ and shear wall connections ${ }^{[23,24]}$. It was found that using sleeve connections in a precast structure could 
effectively prevent buckling of rebar and the sleeves connections had enhanced fire resistance when they were placed in the foundation ${ }^{[15,20]}$.

Fire resistance is an import issue in modern building design. The thermal effects of fire cause a significant reduction in fire resistance. Since the changes of mechanical properties of steel rebar $^{[25]}$, grouting material ${ }^{[26]}$ and the bond ${ }^{[27]}$ between steel and grouting material after a fire, the mechanical performance of grouted sleeve connections may be significantly degraded, thus causing damage to the structures, especially when subjected to seismic conditions. Many researcher studied the post-fire cyclic behavior of RC structures ${ }^{[28,29]}$. It was found that fire caused substantial damage to the structure, resulting in a reduced seismic resistance. Under seismic action, concrete cover is likely to crush, leading to exposure of the connection to elevated temperature. To the authors' best knowledge, seismic responses of grouted sleeve connections after under elevated temperature have not been studied, though, undoubtedly, the post-fire evaluation of the connections in earthquake zones is critically important.

In order to study the seismic responses of grouted sleeve connections after cooling down to room temperature, experimental tests on grouted sleeve connections are carried out under both monotonic and cyclic loading. For comparisons, tests on continuous rebar are also carried out under the same temperature history and loading conditions. The failure models, skeleton curves, hysteresis curves, compression strength and stiffness of the connections are investigated. In order to simulate the constitutive relation of the continuous rebar and the grouted sleeve connections after cooling down to room temperature, a modified hysteretic model for continuous steel rebar and grouted sleeve connection is presented.

\section{Experimental program}

\subsection{Experimental design}

In this study, a total of 16 grouted sleeve connections were tested, of which 8 connections were under monotonic loading and the rest were under cyclic loading. The specimens were heated up to, respectively, $20^{\circ} \mathrm{C}, 200^{\circ} \mathrm{C}, 300^{\circ} \mathrm{C}, 400^{\circ} \mathrm{C}, 500^{\circ} \mathrm{C}, 600^{\circ} \mathrm{C}, 700^{\circ} \mathrm{C}$, and $800^{\circ} \mathrm{C}$ before they were cooled down to room temperature. For comparisons, continuous rebar were also tested for the same loading and the temperature history.

To make fair comparisons, all the connections were used to join rebar of $14 \mathrm{~mm}$ in diameter, which were the same as the connections studied in the authors' previous work ${ }^{[30]}$. As shown in Fig. 1, all the connections are circular, having a sleeve with a diameter and thickness of 46 and $5.5 \mathrm{~mm}$, respectively. The length of the connections and the rebar outside the sleeve are $275 \mathrm{~mm}$ and 190 $\mathrm{mm}$, respectively.

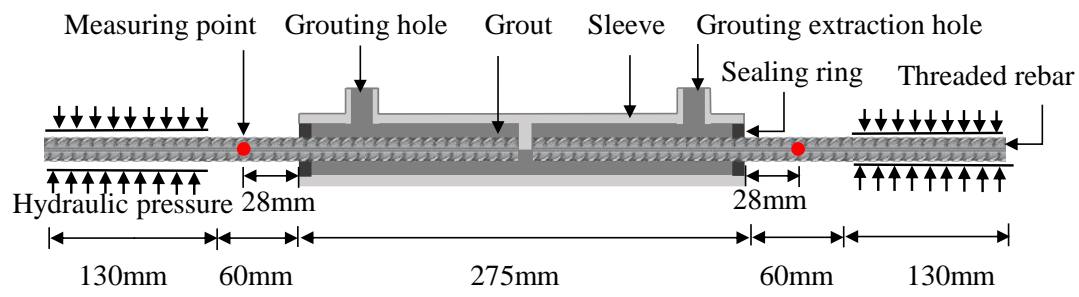

(a) Side view

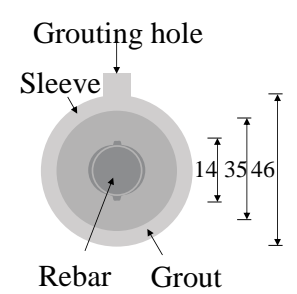

(b) Cross-section

Fig. 1. Construction and dimensions of the grouted sleeve connection 


\subsection{Specimen preparation}

The GT14L sleeves with a yield strength of $355 \mathrm{MPa}$, meeting the requirement of Chinese standard JG/T398-2012 $2^{[31]}$, were used for the tests. HRB400Ф ribbed rebar were cut to $320 \mathrm{~mm}$ long according to the Chinese standard and the size of furnace. The CGMJM-VIII cementitious grout with water to cement ratio of $0.13: 1$ were chosen, which meets the requirement of JGT $408-2013^{[32]}$. All the grouts were from the same patch and all the connections to be tested had nearly the same weight. The measured strength of the grout after 28 days at room temperature is $116 \mathrm{MPa}$. The manufacturing process can be seen in Fig. 2. Prior to pouring, the cementitious grout and water were properly mixed to achieve best possible consistency. The connection and the rebar were placed carefully to avoid any visible eccentricity. The cementitious grout was then injected into the sleeve from the grouting inlet until overflow occurred from the grouting extraction.

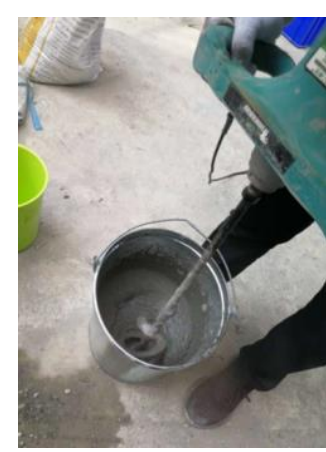

(a) Cementitious grout

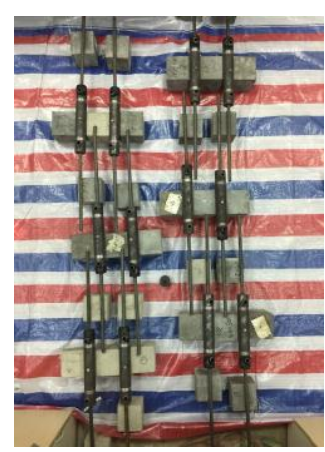

(b) Fixed specimen

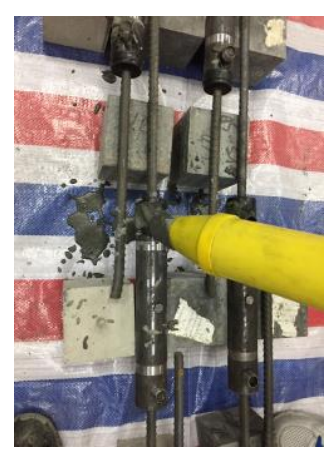

(c) Pour grout

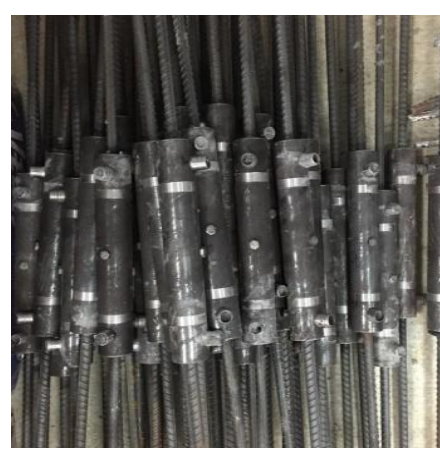

(d) Sample

Fig. 2. Manufacturing process of grout sleeve connections

\subsection{Loading and measuring system}

The specimens were heated in the electric furnace (Fig. 3 (a)) to the target temperature with a heating rate of $5^{\circ} \mathrm{C} / \mathrm{min}$ according to the Chinese test standard ${ }^{[33]}$ and kept under the respective targeting temperature for 3 hours to achieve a uniform temperature distribution within the connection. The specimens were then cooled down to room temperature in the open air.

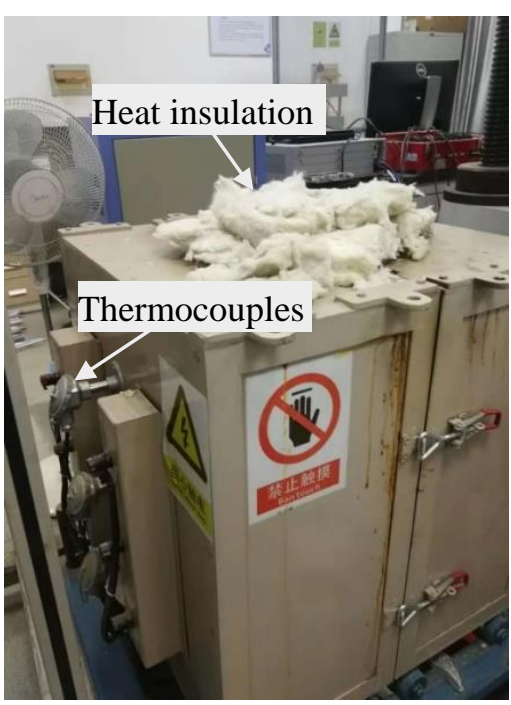

(a) Electric furnace

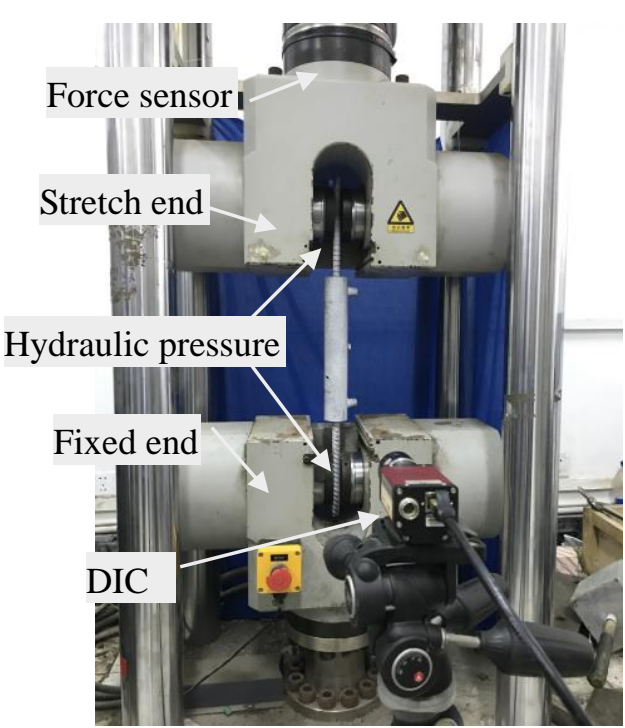

(b) Servo universal testing machine 


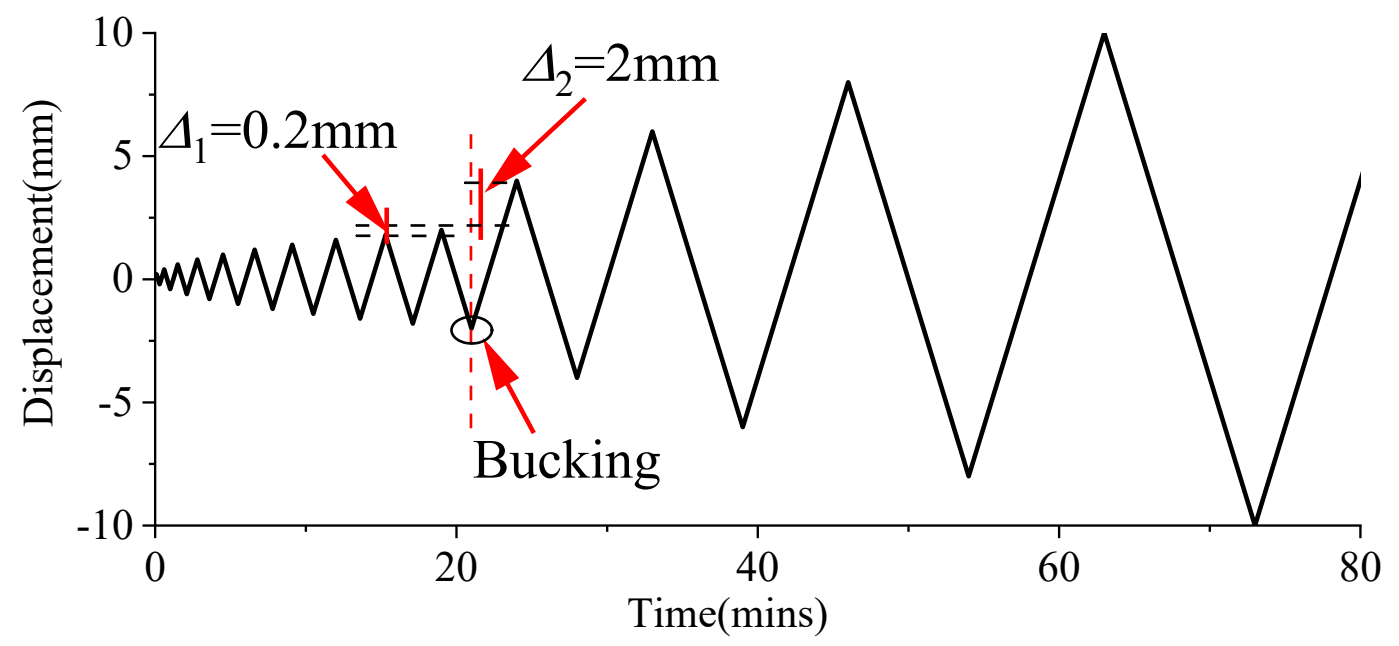

Fig. 4. Cycling loading program

The prepared specimens were installed into the servo universal testing machine (Fig. 3b) and a hydraulic pressure system was used in the tests to prevent the sliding between the crosshead and the specimens. The specimens were then tested under the monotonic and cycling loading, respectively, with a loading speed of $2 \mathrm{~mm} / \mathrm{min}$ according to the Chinese test standard ${ }^{\text {[34] }}$. The cyclic loading program is shown in Fig. 4,where the amplitude of the axial displacement of the specimen increases $0.2 \mathrm{~mm}(0.005 \varepsilon)$ per cycle before buckling occurs and increases $2 \mathrm{~mm}(0.05 \varepsilon)$ per cycle thereafter. The measuring points were selected (Fig.1) according to the requirement of China Standard ${ }^{[35]}$. The distance of the two points is $L=L_{1}+4 d$, where $L_{1}=275 \mathrm{~mm}$ is the length of connection and $d=14 \mathrm{~mm}$ is the diameter of the rebar. The deformation between the two measuring points and the associated loads were respectively recorded continuously using the Imetrum non-contact Digital Image Correlation (DIC) measuring system and the force sensors during the tests.

\section{Experimental results and discussion}

\subsection{Specimens under the monotonic tensile loading}

\subsubsection{Failure modes}

Under the monotonic tensile loading, the failure modes changed from bar breaking (Fig. 5(a)) to bond failure (Fig. 5(b)), depending on the temperature the specimens were cooled down from. When the temperature was below $600^{\circ} \mathrm{C}$, the bond strength between the rebar and the grouting material decreased slightly, while was still greater than the strength of the rebar. Therefore, the rebar outside the sleeve failed first as the stress of the rebar exceeded its strength. When the temperature reached $600^{\circ} \mathrm{C}$, the bond lost its strength significantly. The strength of the rebar was greater than the bond strength, thus, bond failure occurred first. 


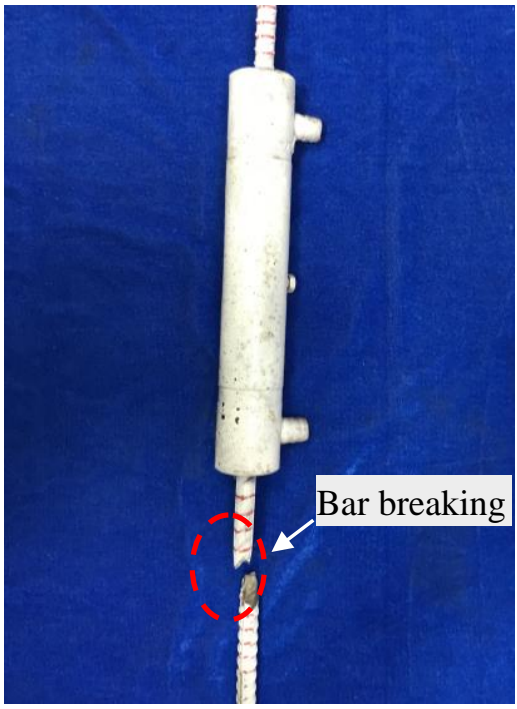

(a) Bar breaking

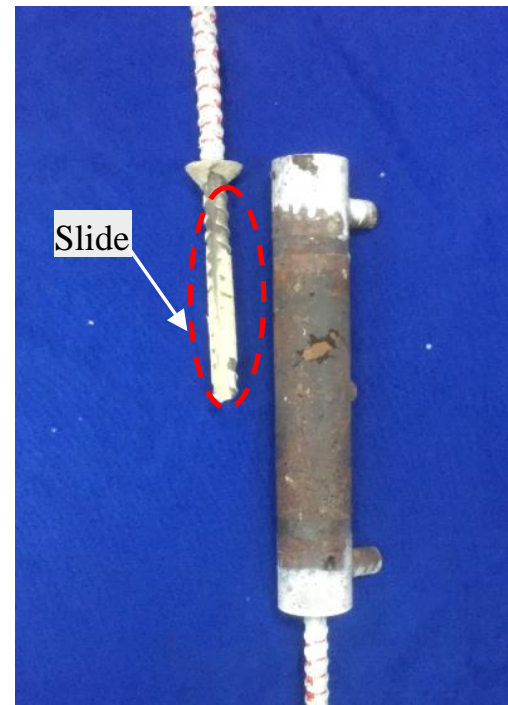

(b) Bond failure

Fig. 5. Failure model of the grouted sleeve connections under the monotonic loading

\subsubsection{Stress-strain curve}

For the continuous rebar under monotonic tensile loading, the stress-strain curves, as shown in Fig. 6(a), are clearly set apart at $600^{\circ} \mathrm{C}$. The rebar carries a much higher stress at the same strain if they are cooled down from a temperature below $600^{\circ} \mathrm{C}$. The initial slopes of the curves are virtually the same for all the temperatures. For the grouted sleeve connections under monotonic loading, as shown in Fig. 6(b), if they are cooled down from a temperature smaller than $600^{\circ} \mathrm{C}$, they fail due to rebar breaking, therefore, the curves of the grouted sleeve connections are the same to those of the continuous rebar shown in Fig. 6(a). If the temperature exceeds $600^{\circ} \mathrm{C}$, the connections fail due to bond failure, at which the stress decreases sharply as slips between the cementitious grout and the rebar take place. Unlike the continuous rebar, the initial slopes of the curves of the grouted sleeve connections decrease with the increase of temperature.

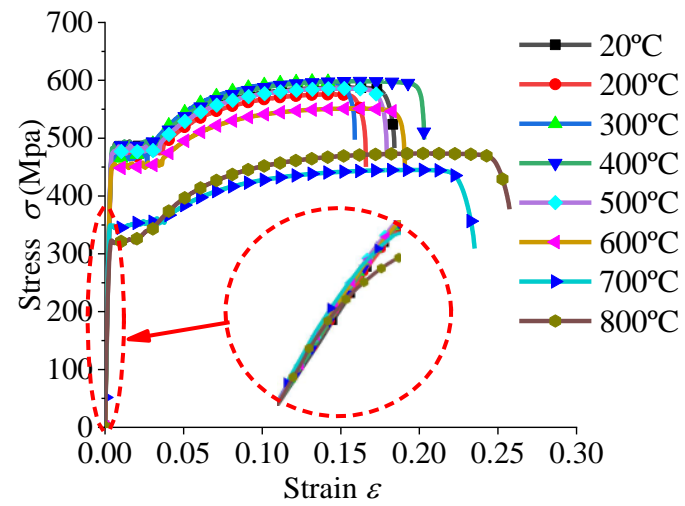

(a) Continuous rebar

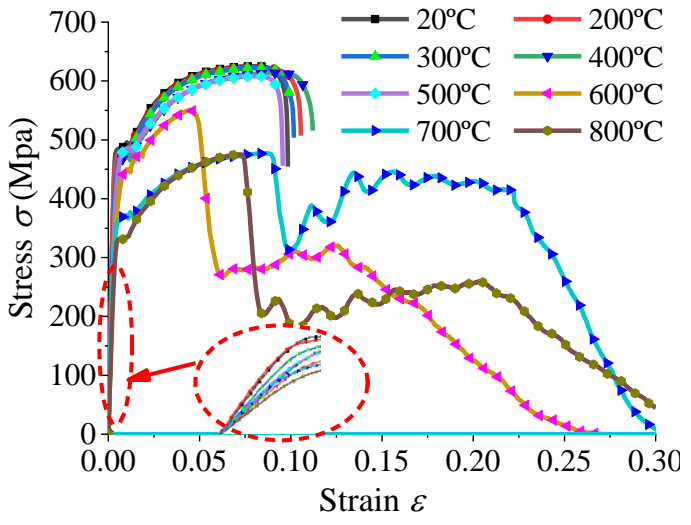

(b) Connection

Fig. 6. Stress-strain curve under monotonic loading

\subsection{Specimens under cyclic loading}

\subsubsection{Failure modes and stress-stain curves}

Under the cyclic loading, buckling (Fig. 7) occurred to both the continuous rebar and the connection due to the plastic hinges, respectively, developed at the middle of the rebar and the ends of the connection when the compressive deformation was sufficiently large. 


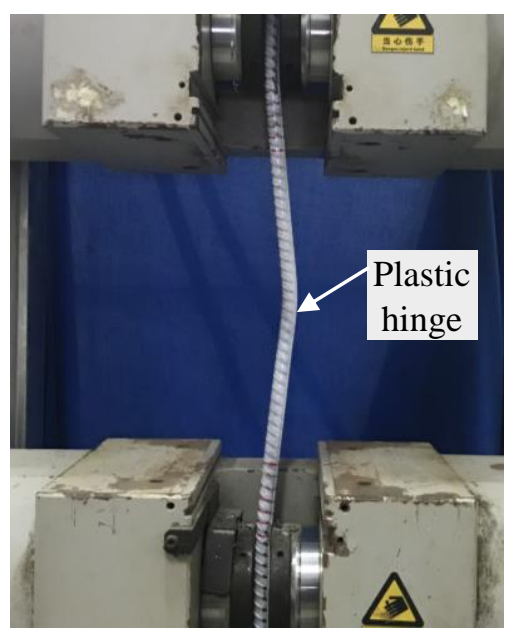

(a) Continuous rebar

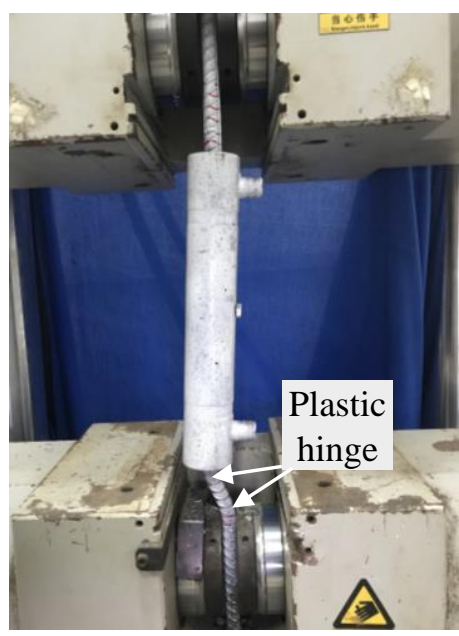

(b) Connections

Fig. 7. Failure model of the continuous rebar and the grouted sleeve connections under cyclic loading 1

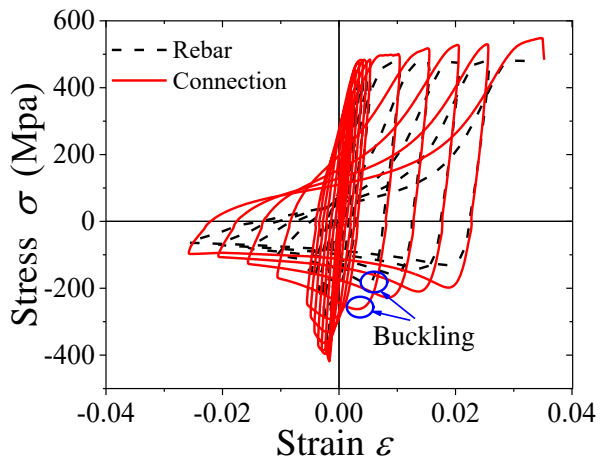

(a) $20^{\circ} \mathrm{C}$

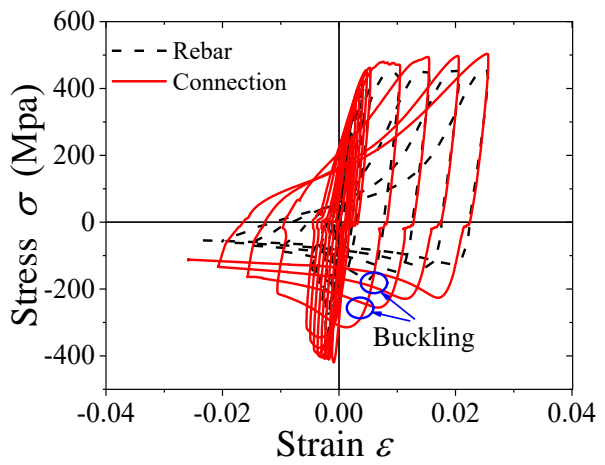

(c) $300^{\circ} \mathrm{C}$

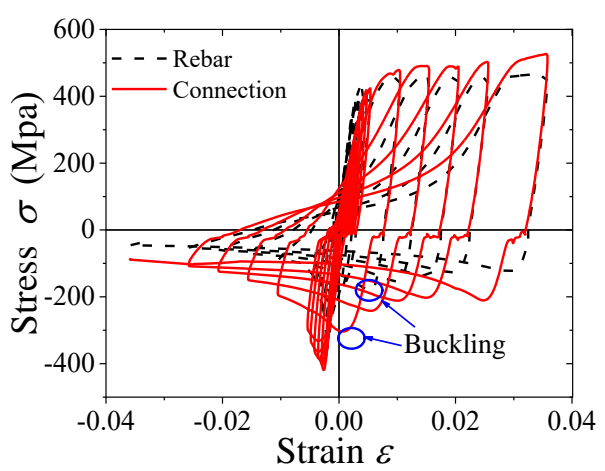

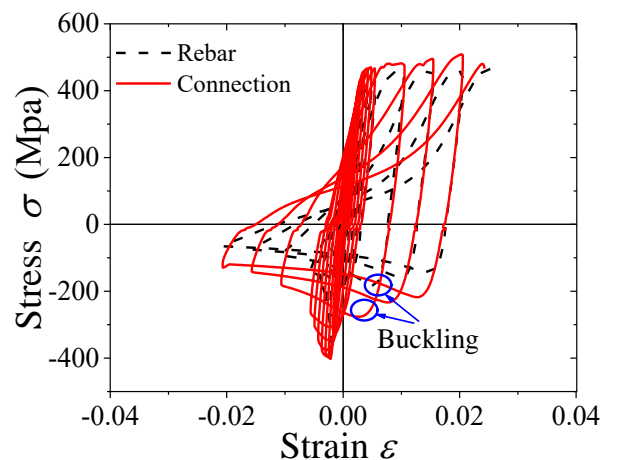

(b) $200^{\circ} \mathrm{C}$

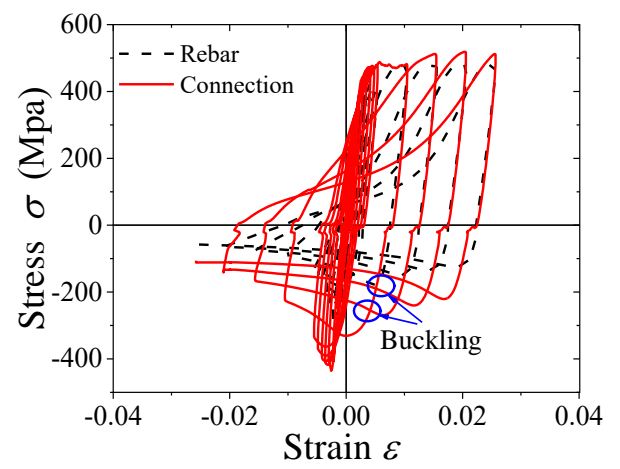

(d) $400^{\circ} \mathrm{C}$

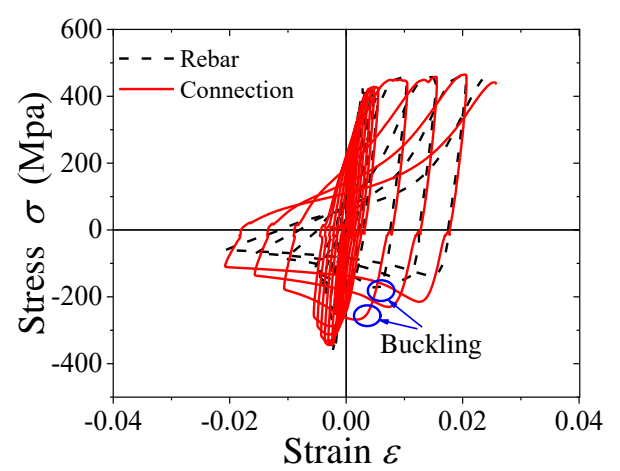


(e) $500^{\circ} \mathrm{C}$

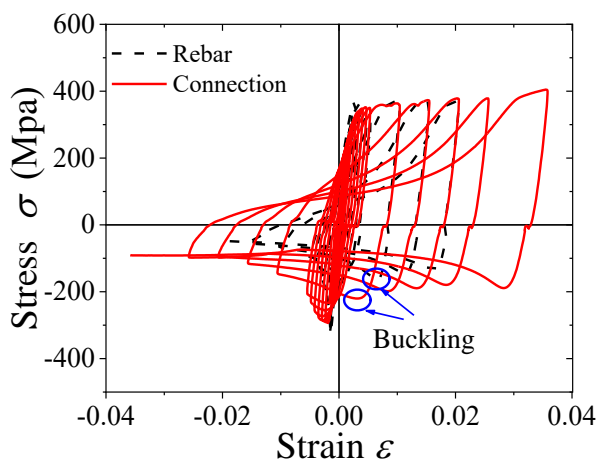

(g) $700^{\circ} \mathrm{C}$ (f) $600{ }^{\circ} \mathrm{C}$

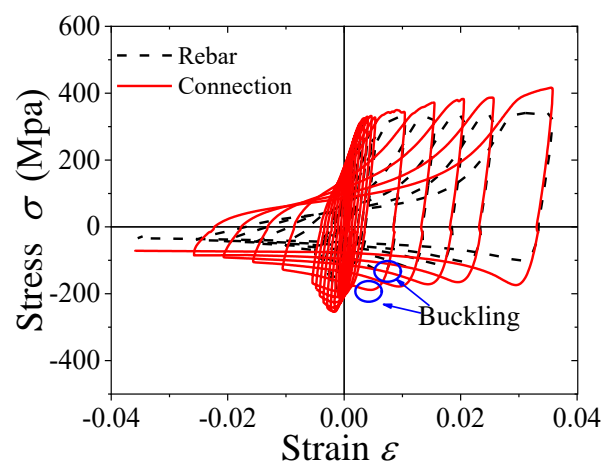

(h) $800^{\circ} \mathrm{C}$

Fig. 8. Stress-strain curves for continuous rebar under cyclic loading ing are shown in Fig. 8Error! Reference source not found.. It can be found that the tensile stress is greater than the compressive stress due to Bauschinger effect ${ }^{[36]}$ when the strain is small. With the increase of strain, plastic hinges are formed in the rebar outside the connection, leading to buckling of the connection and the rapid reduction in the compress stress. The hysteresis curves of the connection (Fig. 8) are similar to those of the rebar (Fig. 9), though they appear more plump, indicating that the grouted sleeve connection has better energy dissipation capacity. It is because that the connection is less likely to buckle and has a higher buckling. In addition, the slope of the reverse curve is greater. Therefore, the area enclosed by under the hysteretic loops a connection is greater, resulting in a higher energy dissipation capacity.

\subsubsection{Skeleton curves in tension}

Skeleton curves are effective representation of strength, deformation and ductility of a material or structural component subjected to cyclic loadings, which can be constructed by tracing the profile of its hysteretic stress-strain curves. The skeleton curves in tension of the rebar and the connections are shown in Fig. 9 (a) and (b), respectively. It can be seen that both the curves of the rebar and the connections are sufficiently close to their respective stress-strain curves from the simple tension (monotonic) tests. At the elastic stage, the slopes of the skeleton curves of the grouted sleeve connections decrease in general with the increase of the peak temperature they have cooled down from. The slopes of the continuous rebar, however, do not show significant differences for the different peak temperatures. At the plastic stage, there are two clusters of the skeleton curves, respectively, for under and above $600^{\circ} \mathrm{C}$, where a higher temperature is generally associated with a lower stress.
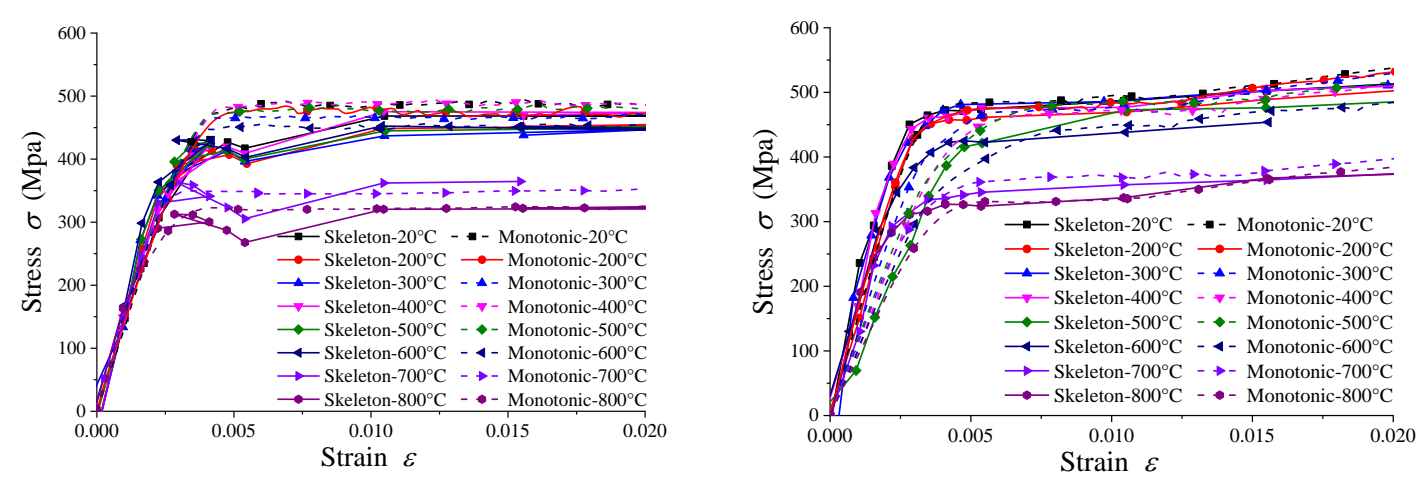
(a) Continuous rebar

(b) Connection

Fig. 9. Skeleton curves of the continuous rebar and the grouted sleeve connections

\subsubsection{Buckling strength}

Buckling strength of a member is defined as the stress at the moment when the member loses its stability. The buckling strength of the continuous rebar and the grouted sleeve connections studied in this paper are shown in Fig. 10(a) and (b), respectively. It can be found that the buckling strength decreases with the increase of strain. For both the rebar and the grouted sleeve connections, if they are cooled down from a temperature below $600^{\circ} \mathrm{C}$, the buckling strength are relatively close to each other. The strength decreases with the increase of the temperature if they are cooled down from a temperature exceeding $600^{\circ} \mathrm{C}$. It can be found also that the buckling strength of the grouted sleeve connection is greater than that of the continuous rebar as the overall stiffness of the connection is greater.

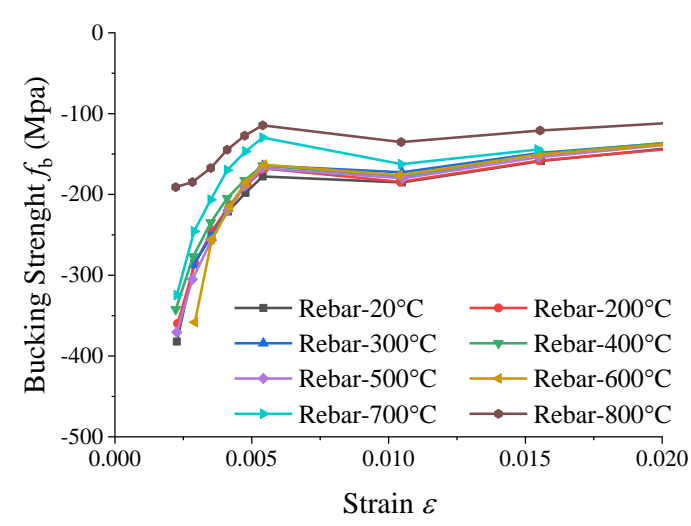

(a) Continuous rebar

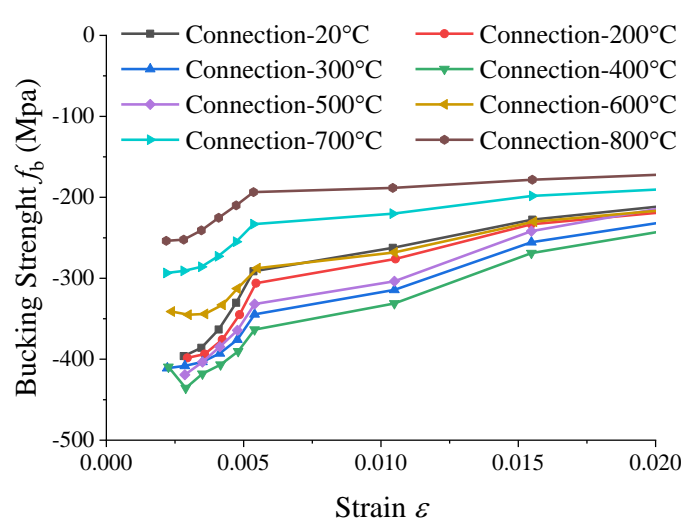

(b) Connection

Fig. 10. Buckling strength of the continuous rebar and the grouted sleeve connections

\subsubsection{Compressive strength}

Compressive strength of a member is defined as the stress at the largest compressive strain. As shown in Fig. 11, the compressive strength of the grouted sleeve connection is close to each other under temperatures below $600^{\circ} \mathrm{C}$ and decreases with the increase of the temperature exceeding $600^{\circ} \mathrm{C}$. The influence of temperature on the connection is similar to that on the continuous rebar for the reason that all the connections fail due to bar breaking. However, the compressive strength of the connection is bigger than that of the continuous rebar. It is due to that the location of the plastic hinge often appears at the middle of the continuous rebar, while the plastic hinge appears at the end of the connection, thus, the lateral deformation of the connection is smaller than that of the continuous rebar. 


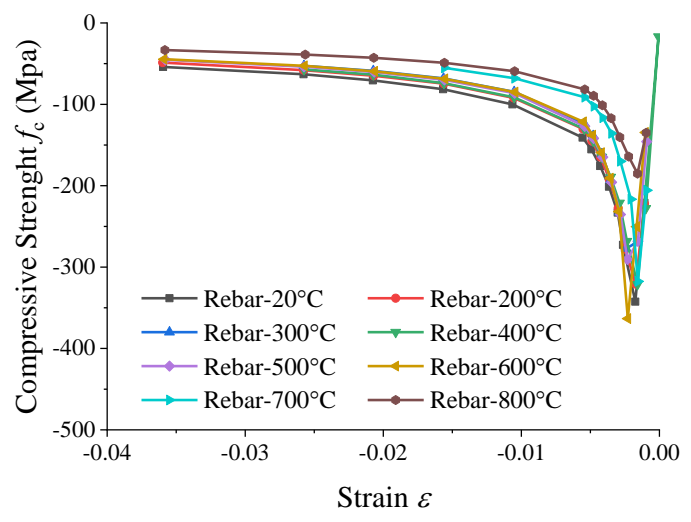

(a) Continuous rebar

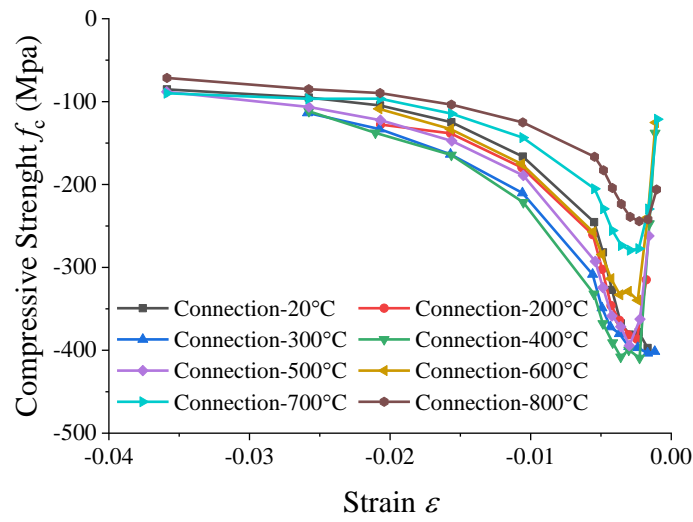

(b) Connection

Fig. 11. Compressive strength of the continuous rebar and the grouted sleeve connections

\section{Cyclic constitutive relation}

\subsection{Hysteresis models}

The GMP model ${ }^{[37,38]}$ was proposed by Giuffre, Menegotto and Pinto for simulating the hysteretic relation of steel. In Fig.12(a), the solid line is the stress-strain curve and the dotted lines (a) and (b) are the asymptotes of the gradients of the curves, $E s$ and $E s_{1}$, respectively, at different stages of loading; $\varepsilon_{s 1}, \sigma_{s 1}$ are the respective strain and stress at the point where the two asymptotes meet (point A). $\varepsilon_{s a}, \sigma_{s a}$ are the respective strain and stress at the point where strain reversal occurs (point B). $\varepsilon_{s o}, \sigma_{s o}$ are the respective strain and stress at the yield point of the bilinear envelope. The stress-strain equations are

$$
\begin{gathered}
\sigma^{*}=\beta \varepsilon^{*}+(1-\beta) \frac{\varepsilon_{s}^{*}}{\left[1+\left(\varepsilon_{s}^{*}\right)^{R}\right]^{1 / R}} \\
\varepsilon_{s}^{*}=\frac{\varepsilon_{s}-\varepsilon_{s a}}{2 \varepsilon_{s o}} \\
\sigma_{s}^{*}=\frac{\sigma_{s}-\sigma_{s a}}{2 \sigma_{s o}}
\end{gathered}
$$

where $\varepsilon_{s}, \sigma_{s}$ are the strain and stress, respecively; $\varepsilon_{s}^{*}=\varepsilon_{s} / \varepsilon_{s o}, \sigma_{s}^{*}=\sigma_{s} / \sigma_{s o}$ are the normaliezed strain and stress; . $\beta=E_{s 1} / E_{s}$ is the ratio between the hardening modulus, $E_{s 1}$, and the tangent modulus of elasticity, $E_{s}$, at the origin. $R=R_{0}-a_{1} \xi_{p}^{n} /\left(a_{2}+\xi_{p}^{n}\right)$ is a constant that takes into account the Baushinger effect, where, $R_{0}, \alpha_{1}$ and $\alpha_{2}$ are material constants; and $\xi_{p}^{n}$ is the absolute value of the plastic strain of the most recent excursion. 


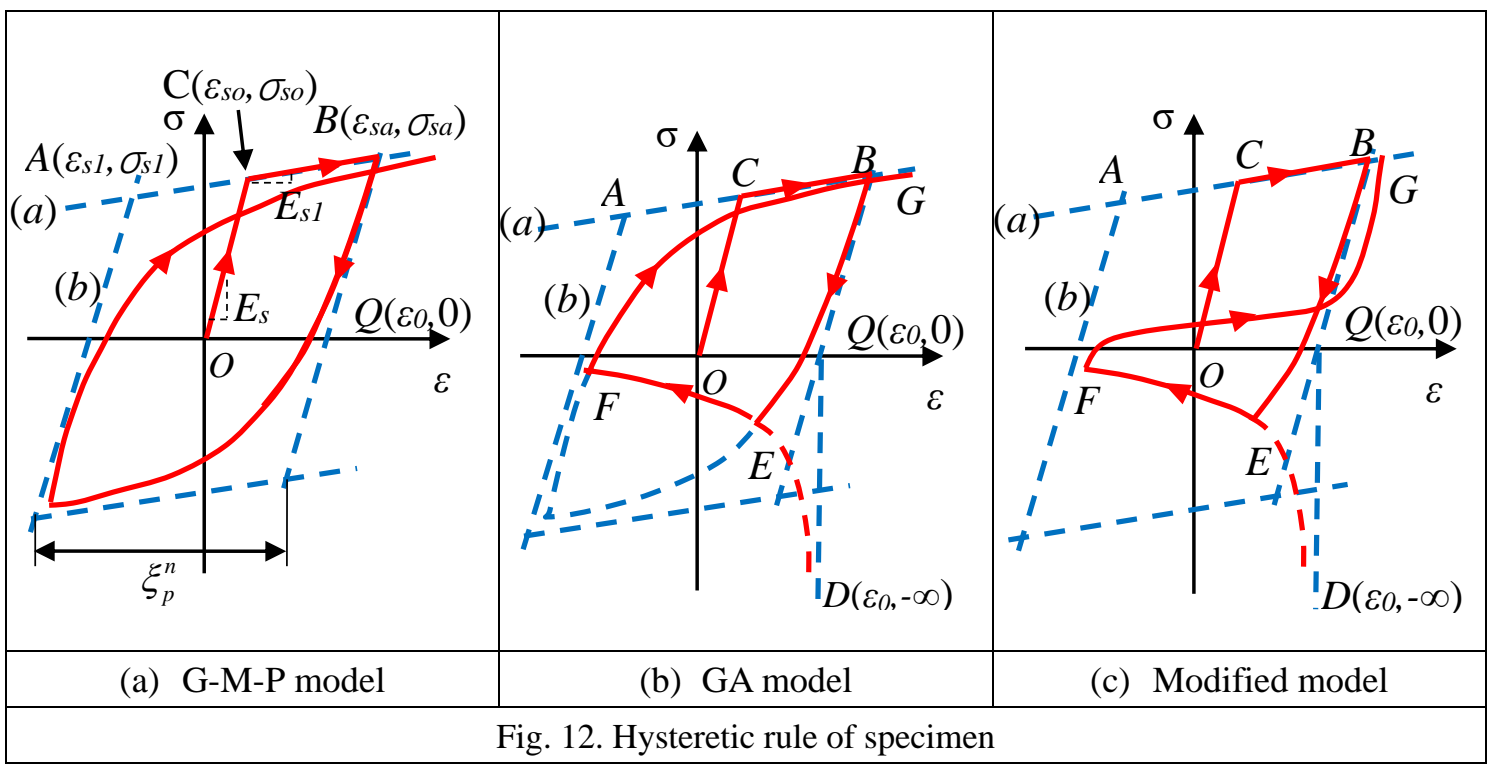

However, the GMP model ignores the possibility of buckling when the rebar is under compression. To solve the problem, Gomes and Appleton proposed the GA model ${ }^{[39]}$ to consider the effect of buckling. From the experiments shown previously, the plastic hinges formed at both the ends and the middle of the rebar. The equilibrium of the buckled steel rebar is shown in Fig. 13 (a). On the basis of the equilibrium, the stress-strain relation from the GA model shown in Fig. 12(b) was proposed as

$$
\sigma=\frac{2 \sqrt{2} W_{p} \sigma_{y}}{A L} \frac{1}{\sqrt{\varepsilon-\varepsilon_{0}}}
$$

where, $W p$ is the plastic section modulus; $\sigma_{y}$ is the yield stress of the rebar; $A$ is the sectional area of the rebar; $L$ is the compressive length; and $\varepsilon_{0}$ is the strain at zero stress. In the GA model, Eq.(4) can be applied during the compressive stage (EF branch), along with the stress-strain relation in the GMP model applied at the unloading and reverse loading stages. As shown in Fig. 13 (b), the rebar is subjected to both tension and bending rather than uniaxial tension only when the load applied to the bucked rebar changes its direction.

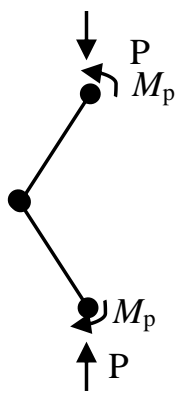

(a) Compressive load

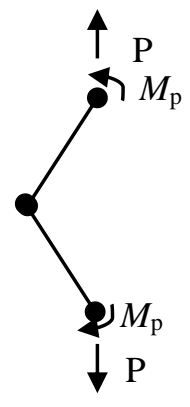

(b) Tensile load

Fig. 13. Equilibrium relationship of buckled steel rebar

To include the effect of possible buckling at other stages in the GA model, Yang ${ }^{[40]}$ proposed a modified model considering the effect of buckling at the reverse loading stage (FG branch), and the stress at this stage can be expressed as 
3 where $\sigma^{*}$ is the stress in the GMP model at the stage of reverse loading. $\alpha$ is a modification

4 factor that is expressed as:

$$
\alpha=\beta_{r} \frac{2 \sqrt{2} W_{p}}{A L} \frac{1}{\sqrt{\varepsilon-\varepsilon_{0}}}
$$

\begin{tabular}{ccccccccc}
\hline \multicolumn{4}{c}{ Grouted sleeve connection } & \multicolumn{5}{c}{ Continuous rebar } \\
\hline \multirow{2}{*}{ Temperature } & $E_{s T}$ & $\varepsilon_{s T}$ & $\beta_{r T}$ & $R_{0 T}$ & $E_{s T}$ & $\varepsilon_{s T}$ & $R_{0 T}$ & $\beta_{r T}$ \\
\hline $20^{\circ} \mathrm{C}$ & $2.6 \mathrm{E} 05$ & $1.80 \mathrm{E}-03$ & 2.24 & 3.00 & $2.3 \mathrm{E} 05$ & $2.0 \mathrm{E}-03$ & 2.76 & 1.35 \\
$200^{\circ} \mathrm{C}$ & $2.5 \mathrm{E} 05$ & $1.87 \mathrm{E}-03$ & 2.42 & 2.78 & $2.3 \mathrm{E} 05$ & $2.0 \mathrm{E}-03$ & 2.72 & 1.46 \\
$300^{\circ} \mathrm{C}$ & $2.5 \mathrm{E} 05$ & $2.00 \mathrm{E}-03$ & 3.37 & 1.99 & $2.3 \mathrm{E} 05$ & $2.0 \mathrm{E}-03$ & 2.79 & 1.38 \\
$400^{\circ} \mathrm{C}$ & $2.2 \mathrm{E} 05$ & $2.00 \mathrm{E}-03$ & 3.37 & 1.99 & $2.3 \mathrm{E} 05$ & $2.0 \mathrm{E}-03$ & 2.58 & 1.46 \\
$500^{\circ} \mathrm{C}$ & $2.2 \mathrm{E} 05$ & $2.14 \mathrm{E}-03$ & 2.88 & 2.33 & $2.3 \mathrm{E} 05$ & $2.0 \mathrm{E}-03$ & 2.74 & 1.41 \\
$600^{\circ} \mathrm{C}$ & $2.1 \mathrm{E} 05$ & $2.14 \mathrm{E}-03$ & 2.91 & 2.31 & $2.3 \mathrm{E} 05$ & $2.0 \mathrm{E}-03$ & 2.72 & 1.35 \\
$700^{\circ} \mathrm{C}$ & $1.9 \mathrm{E} 05$ & $1.90 \mathrm{E}-03$ & 2.50 & 2.69 & $1.8 \mathrm{E} 05$ & $2.0 \mathrm{E}-03$ & 5.64 & 1.19 \\
$800^{\circ} \mathrm{C}$ & $1.8 \mathrm{E} 05$ & $1.90 \mathrm{E}-03$ & 2.68 & 2.51 & $1.6 \mathrm{E} 05$ & $2.0 \mathrm{E}-03$ & 3.76 & 1.26 \\
\hline
\end{tabular}

where $\beta_{r}$ is a modification coefficient depending on the possibility of buckling of the rebar. A smaller $\beta_{r}$ indicates that the member is more likely to buckle. The modified model can be seen in Fig. 13(c).

\subsection{Model parameter}

Based on the experimental results presented in the previous sections, the modified hysteretic model by Yang $^{[40]}$ is extended to represent the hysteretic relation of steel rebar and grouted sleeve connections. The model parameters are determined by calibrations using the test results and are listed in Table 1.

Table 1 Parameters calibration
17 


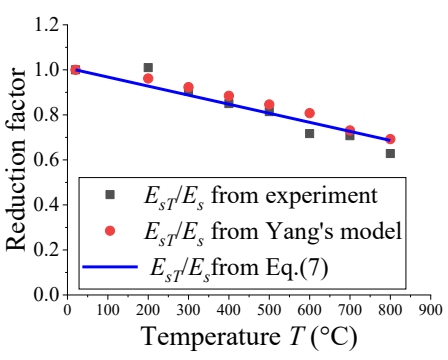

(a) Elastic modulus

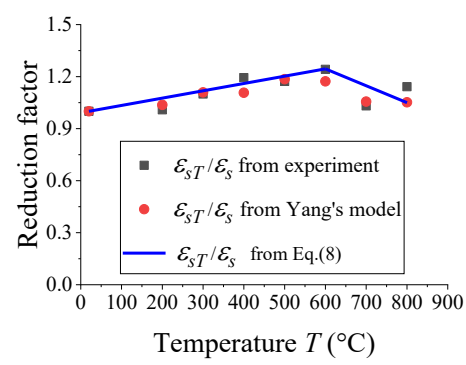

(b) Yield strain

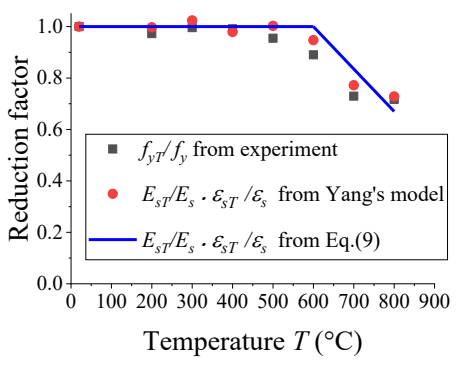

(c) Tension strength

Fig. 14. Comparison among reduction factors, the calibrated parameters in the hysteretic model and fitting equations fitting parameters of the grouted sleeve connection

Fig.14 shows the reduction factor of the grouted sleeve connections. It can be found that the reduction factors of elestic mudulus $E_{s}$, yield strain $\varepsilon_{s}$ and tension strength $f_{y}$ calculated from the test results, the calibrated parameters in Yang's modified hysteretic model and the analytical equations obtained by fitting the parameters agree with each other well.

The ratio of the tangent modulus at the early stage of loading, $E_{s T} / E_{s}$, decreases with the increase of temperature, where, $E_{s T}$ is the tangent modulus of elasticity of the connnection after colling down from heating. The ratio of yield strain of the connection between the heated and unheated, $\varepsilon_{s T} / \varepsilon_{s}$, where $\varepsilon_{s T}$ is the yield strain after cooling down from heating, increases with the increase of the heating temperature of below $600^{\circ} \mathrm{C}$, while decreases when the temperature exceeds $600^{\circ} \mathrm{C}$. The values of $\left(E_{s T} / E_{s}\right) \cdot\left(\varepsilon_{s T} / \varepsilon_{s}\right)$ keep constant and then decrease when the temperature exceeds $600^{\circ} \mathrm{C}$.

\subsection{Model validation}

Using the calibrated parameters, the hysteretic stress-strain curves of the grouted sleeve connections and the rebar are predicted by the Yang's modified hysteretic model. The comparisons of the hysteretic stress-strain curves between the experiments and the hysteretic model for the continuous rebar and the grouted sleeve connection under cyclic loading are shown in Fig. 15Error! Reference source not found. and Fig. 16Error! Reference source not found., respectively. It can be found that the hysteretic model and the experimental results are in good agreement. For the grouted sleeve connection, the hysteretic model agree well with the experiments at the stages of both compressive unloading and reverse loading. For the continuous rebar, large differences between the experimental results and the modified model are observed in the reverse loading stage (FG branch in Fig.12 (c)). It is because that the length to diameter (L/d) ratio of the continuous rebar is too big and the stiffness of the rebar is relatively small, resulting in the small slope of the reverse loading stage. However, in a real design, the length to diameter ratio of the continuous rebar is not likely to be 28 used in this paper, which was tested in this paper just for the sake of making comparisons with the grouted sleeve connections. 


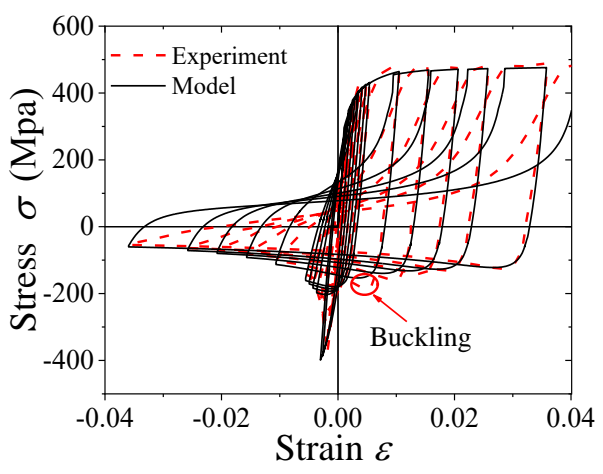

(a) $20^{\circ} \mathrm{C}$

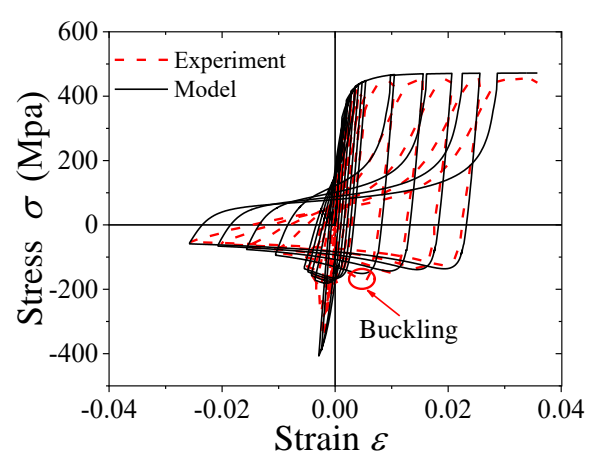

(c) $300^{\circ} \mathrm{C}$

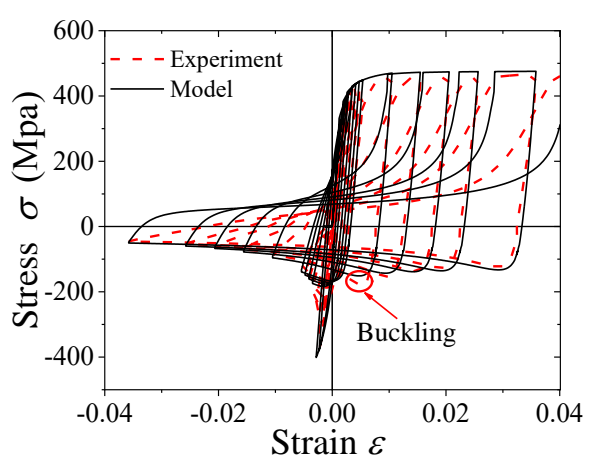

(e) $500^{\circ} \mathrm{C}$

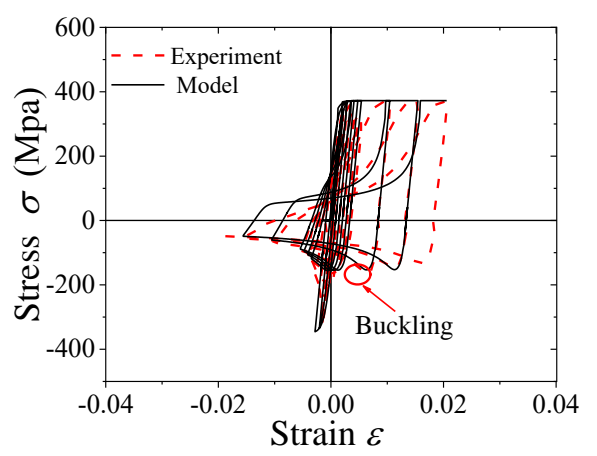

(g) $700^{\circ} \mathrm{C}$

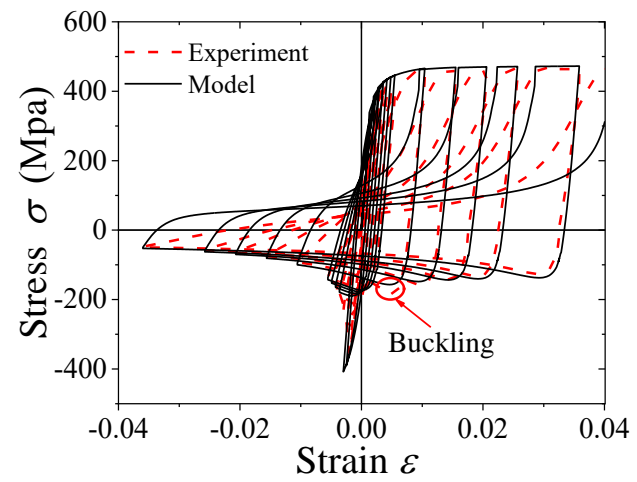

(b) $200^{\circ} \mathrm{C}$

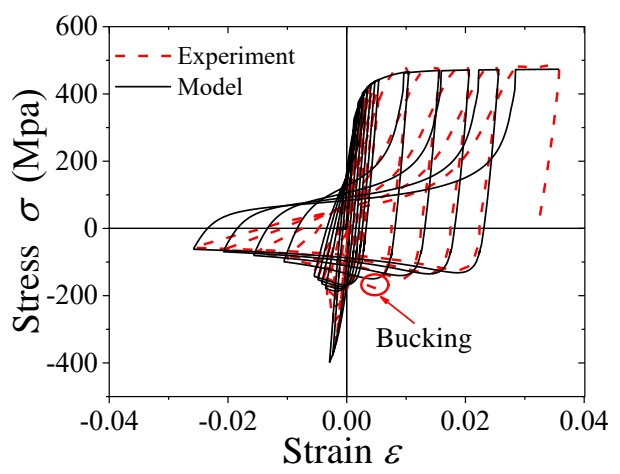

(d) $400^{\circ} \mathrm{C}$

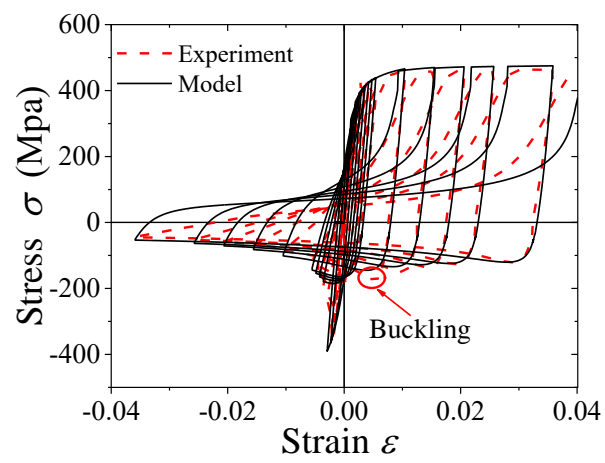

(f) $600^{\circ} \mathrm{C}$

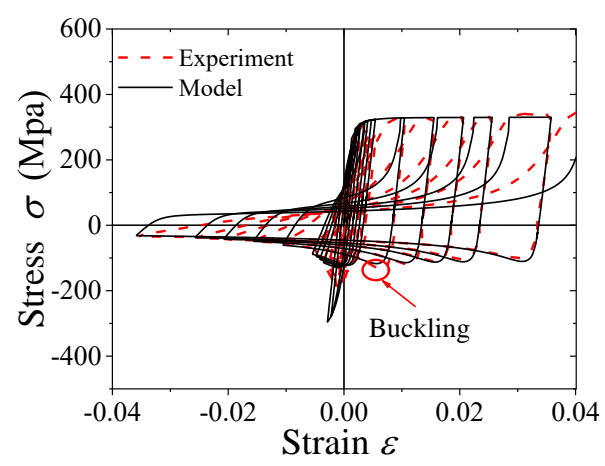

(h) $800^{\circ} \mathrm{C}$

Fig. 15. Stress-strain curves for continuous rebar under cyclic loading 


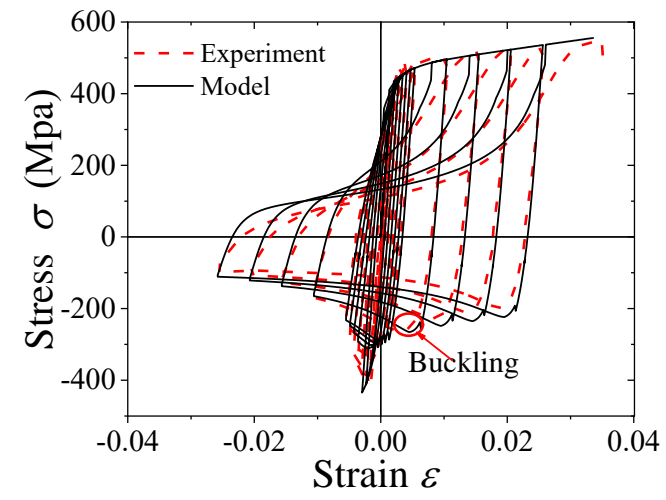

(a) $20^{\circ} \mathrm{C}$

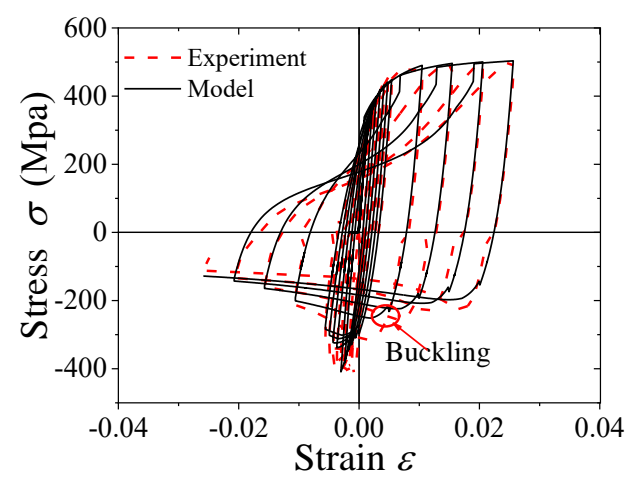

(c) $300^{\circ} \mathrm{C}$

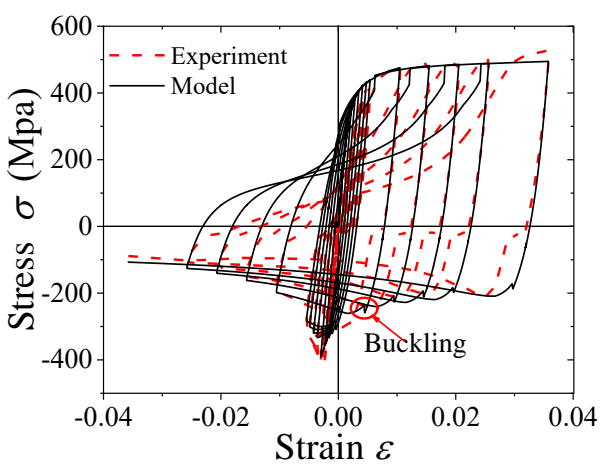

(e) $500^{\circ} \mathrm{C}$

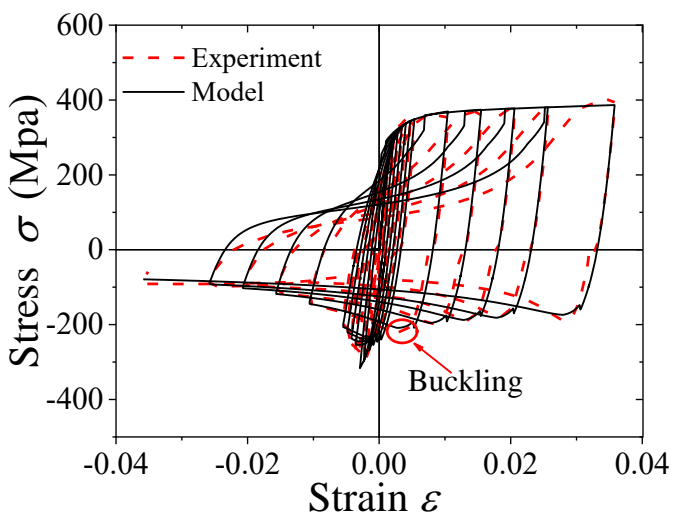

(g) $700^{\circ} \mathrm{C}$

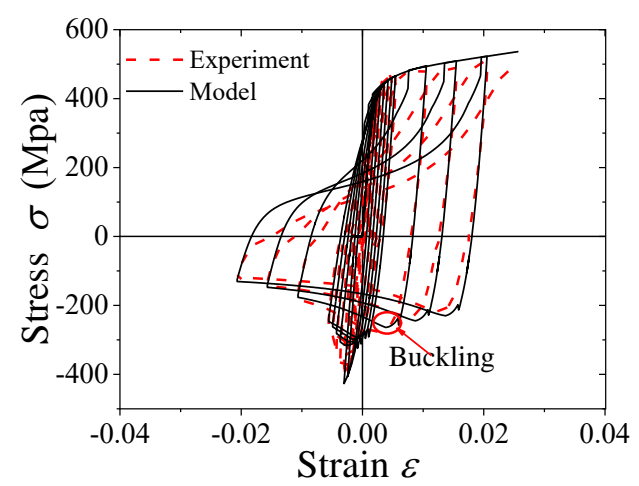

(b) $200^{\circ} \mathrm{C}$

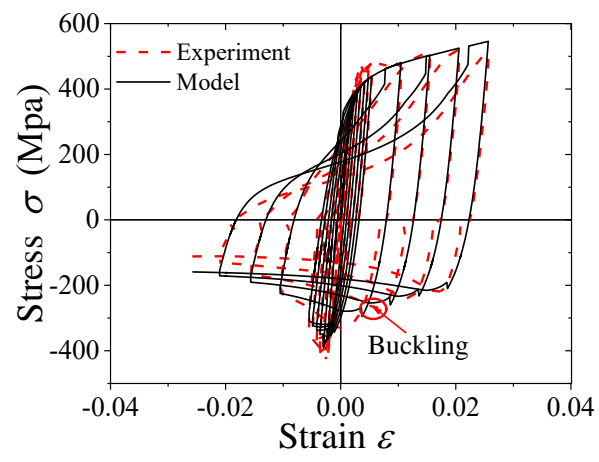

(d) $400^{\circ} \mathrm{C}$

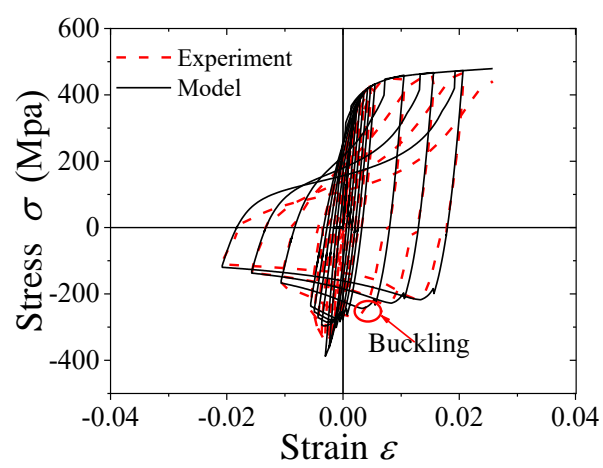

(f) $600^{\circ} \mathrm{C}$

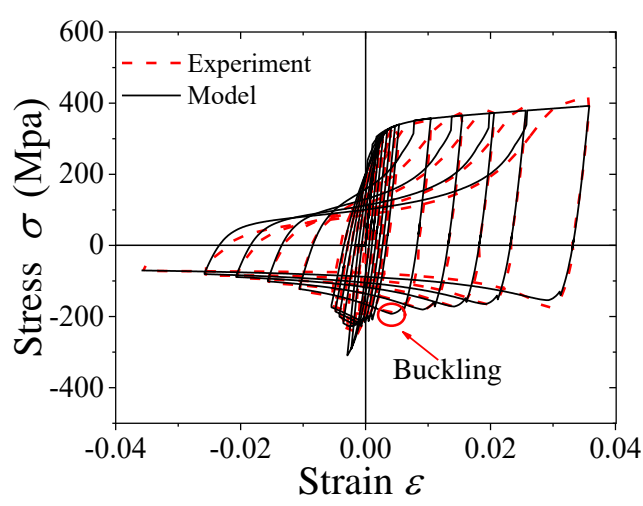

(h) $800^{\circ} \mathrm{C}$

Fig. 16. Stress-strain curves for grouted sleeve connection under cyclic loading 


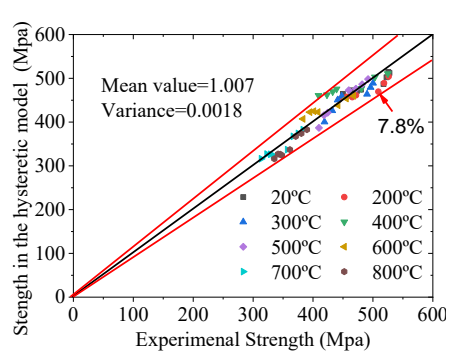

(a) Tensile strength

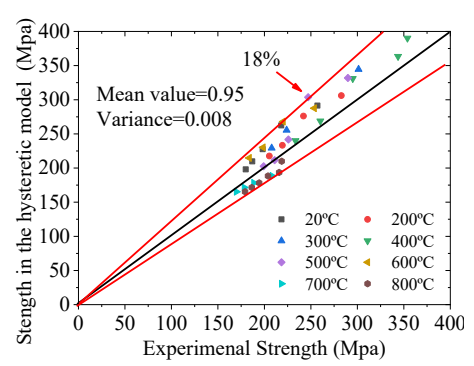

(b) Buckling strength

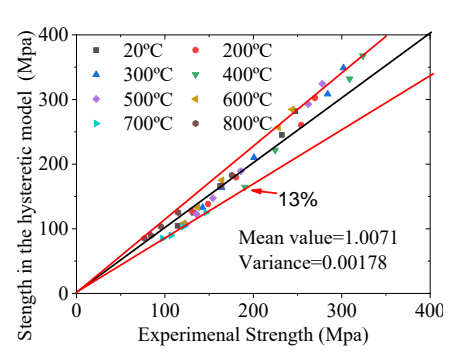

(c) Compressive strength

Fig. 17. Comparison of strength between experiment and hysteretic model of continuous rebar

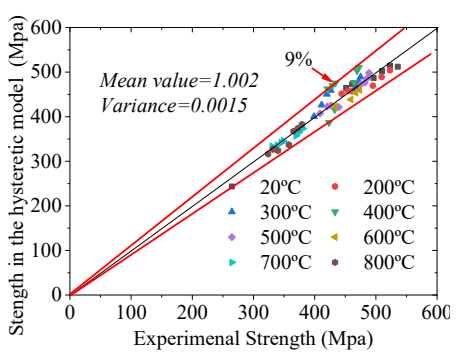

(a) Skeleton curve

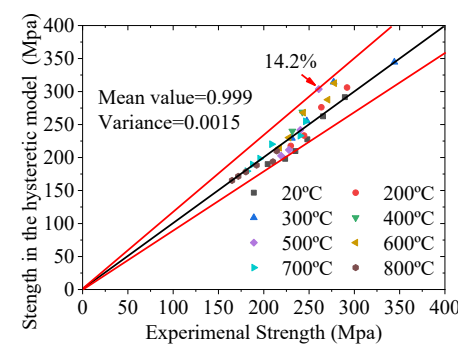

(b) Buckling strength

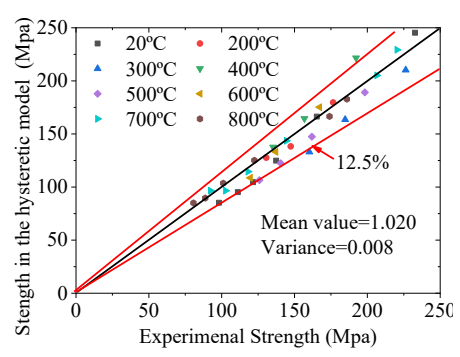

(c) Compressive strength

Fig. 18. Comparison of strength between experiment and hysteretic model of connections

The comparisons of the strength (tensile strength, compressive strength and buckling strength) between the results from the experiments and the hysteretic model for the continuous rebar and the grouted sleeve connections are shown in Fig. 17 and Fig. 18, respectively. Once again, excellent agreement between the two sets of results are evident, which demonstrate that the modified Yang's hysteretic model with the newly calibrated parameters is capable of predicting the strengths of the rebar and the connections.

\section{Conclusion}

In this paper, experimental investigations were carried out to investigate the cyclic behavior of grouted sleeve connections that had been heated to and cooled down from a temperature. The effect of the temperature on the failure modes, skeleton curves, compressive strength and buckling strength of the grouted sleeve connections were studied. After calibration with the test results, the modified Yang's hysteretic model for the cyclic stress-strain curve of grouted sleeve connections was presented and validated. From the present study, the following conclusions are drawn:

1) Under the monotonic loading, the failure mode of the grouted sleeve connection changes from bar breaking to bond failure as the temperature increases. Under the cyclic loading, buckling occurs due to plastic hinges developed at the ends of the connection when the compressive deformation is sufficiently large.

2) The skeleton curves, compressive strength and buckling strength of the grouted sleeve connection after cooling down from different peak temperatures are close to each other when the temperature does not exceed $600^{\circ} \mathrm{C}$. The post-heated strength decreases with the increase of the peak temperature that exceeds $600^{\circ} \mathrm{C}$; The Skeleton curves of the connections are close to those of the continuous rebars while the compressive and buckling strength of the connections are greater than those of the continuous rebars. 
3) The modified Yang's hysteretic model considers the influence of buckling on the unloading stage in compression. The model is capable of accurately simulating steel and grouted sleeve connections subjected to cycling loading, which is in good agreement with experimental results.

It is also worthy of mention that the accuracy of the modified Yang's hysteretic model is limited in the reverse stage for continuous rebar if the length to diameter $(\mathrm{L} / \mathrm{d})$ ratio is too big. Meanwhile, the deformation in the tests reported in this paper is relatively small $(<0.04 \varepsilon)$, thus, no bond-slip failure has been observed in the tests. The on-going work include developing a model that will be capable of accurately simulating rebars with large length to diameter ratio. Seismic tests will also be carried out to study the failure modes with large deformation.

\section{Acknowledge}

The authors are grateful for the financial support from the National Key Research and Development Program of China (2016YFC0701402).

\section{References}

[1] Y. Liu, Y. Wang, G. Fang, et al., A preliminary study on capsule-based self-healing grouting materials for grouted splice sleeve connection, Constr. Build. Mater.170 (2018) 418-423. [2] J.H. Ling, A.B. Abd. Rahman, I.S. Ibrahim, et al., Behaviour of grouted pipe splice under incremental tensile load, Constr. Build. Mater. 33 (2012) 90-98.

[3] J.H. Ling, A.B .Abd. Rahman, I.S. Ibrahim, et al., Tensile capacity of grouted splice sleeves, Eng. Struct. 111(2016) 285-296.

[4] A.A. Sayadi, A.B.A. Rahman, M.Z.B. Jumaat, et al., The relationship between interlocking mechanism and bond strength in elastic and inelastic segment of splice sleeve, Constr. Build. Mater. 55 (2014) 227-237.

[5] A.B.A. Rahman, L.H. Yoon, I.S Ibrahim, et al. Performance of Grouted Splice Sleeves with Tapered Bars under Axial Tension, Appl. Mech. Mater. $789-790$ (2015) 1176-1180.

[6] E. Henin, G. Morcous. Non-proprietary bar splice sleeve for precast concrete construction, Eng. Struct. 83 (2015) 154-162.

[7] H. Yuan, Z. Zhu, CJ Naito, et al., Tensile behavior of half grouted sleeve connections: Experimental study and analytical modeling, Constr. Build. Mater. 152 (2017) 96-104.

[8] X.L. Zhao, P. Grundy, Y.T. Lee, Grout Sleeve Connections under Large Deformation Cyclic Loading, Proceedings of The Twelfth International offshore and polar engineering conference, (2002) 53-59.

[9] H. Kim, Structural Performance of Steel Pipe Splice for SD500 High-strength Reinforcing Bar under Cyclic Loading, Archit. Res. 10(1) (2008) 13-23.

[10] F. Lin, X. Wu, Mechanical Performance and Stress-Strain Relationships for Grouted Splices Under Tensile and Cyclic Loadings, Int. J. Concr. Struct. M. 10 (4) (2016) 435-450.

[11] Y. Zheng, Z. Guo, Structural Performance of Innovative Grout Sleeve Splicing for Rebars under Cyclic Loading, J. Hunan. U.: Nat. Sci.Ed. 43(11) (2016) 131-140.

[12] C. Xu, H. Liu, X. Du, Experimental study on connection performance of grouted sleeve splicing for rebars under high stress repeated tension-compression loading, J. Build. Struct. 39(12) 
(2018) 178-184.

[13] A. Belleri, P Riva, Seismic performance and retrofit of precast concrete grouted sleeve connections, Pci J. 57(1) (2012) 97-109.

[14] N. Tullini, F. Minghini, Cyclic test on a precast reinforced concrete column-to-foundation grouted duct connection, B. Earthq. Eng. 18 (2) (2020).

[15] M.J. Ameli, D.N. Brown, J.E. Parks, et al.,Seismic Column-to-Footing Connections Using Grouted Splice Sleeves, ACI Struct. J. 113(5) (2016) 1021-1030.

[16] B. Dal. Lago, G. Toniolo, M. Lamperti. Tornaghi, Influence of different mechanical column-foundation connection devices on the seismic behaviour of precast structures, B. Earthq. Eng. 14 (12) (2016) 1-24.

[17] V. Popa, A. Papurcu, D. Cotofana, et al., Experimental testing on emulative connections for precast columns using grouted corrugated steel sleeves, B. Earthq. Eng. 13(8) (2015) 2429-2447. [18] N. Buratti, L. Bacci, C. Mazzotti, Seismic behavoiur of grouted sleeve connections between foundations and precast columns, Second European Conference on Earthquake Engineering and Seismology,2014.

[19] Q. Yan, T. Chen, Z. Xie, Seismic experimental study on a precast concrete beam-column connection with grout sleeves, Eng. Struct. 155 (2018) 330-44.

[20] M.J. Ameli, J.E. Parks, D.N. Brown, et al., Seismic evaluation of grouted splice sleeve connections for reinforced precast concrete column-to-cap beam joints in accelerated bridge construction, Pci J. 60(2) (2015) 80-103.

[21] N. Tullini, F. Minghini, Grouted sleeve connections used in precast reinforced concrete construction - Experimental investigation of a column-to-column joint, Eng. Struct.127 (2016) 784-803.

[22] M.J. Ameli, C.P. Pantelides. Seismic Analysis of Precast Concrete Bridge Columns Connected with Grouted Splice Sleeve Connectors, J. Struct. Eng. 143(2) (2016) 04016176.1-04016176.13.

[23] G. Xu, Z. Wang, B. Wu, et al.,Seismic performance of precast shear wall with sleeves connection based on experimental and numerical studies, Eng. Struct. 150 (2017) 346-58. [24] Y. Peng, J. Qian, Y. Wang, Cyclic performance of precast concrete shear walls with a mortar-sleeve connection for longitudinal steel bars, Mater. Struct. 49(6) (2016) 2455-69. [25] Jyri, Outinen, Pentti, Mkelinen. Mechanical properties of structural steel at elevated temperatures and after cooling down), Fire. Mater. 28(2-4) (2010) 237-51.

[26] A. Mendes, J.G. Sanjayan, F. Collins, Effects of slag and cooling method on the progressive deterioration of concrete after exposure to elevated temperatures as in a fire event, Mater. Struct. 44(3) (2011) 709-718.

[27] R.H. Haddad, L.G. Shannis. Post-fire behavior of bond between high strength pozzolanic concrete and reinforcing steel, Constr. Build. Mater. 18(6) (2004) 425-435. [28] L. Lu, J. Qiu, Y. Yuan, J. Tao, et al. Large-scale test as the basis of investigating the fire-resistance of underground RC substructures, Eng. Struct. 178 (JAN.1) (2019) 12-23. [29] H. Zhao, H. Yu, Y. Yuan, P. Li, et al., Cyclic loading behavior of a repaired subway station after fire exposure, Tunn.Undergr.Sp.Tech. 84 (2019) 210-217.

[30] T. Wang, H.M. Xu, M. Yu, L.H. Xu, et al., Experimental investigation on the failure modes of grouted sleeve connections under thermal and mechanical loads, Eng. Fail.Anal. 109 (2020) 104246. 
1 [31] JG/T 398-2012, The Grouting Coupler for Rebars Splicing, Ministry of Housing and

2 Urban-Rural Development of China, Beijing, 2012.

3 [32] JG/T 408-2013, Cementitious Grout for Coupler of Rebar Splicing, Ministry of Housing and 4 Urban-Rural Development of China, Beijing, 2013.

5 [33] GB/T228.2-2015, Metallic materials-Tensile testing-Part 2:Method of test at elevated,

6 General Administration of Quality Supervision,Inspection and Quarantine, Beijing, 2015.

7 [34] JGJ 107-2010, Technical Specification for Mechanical Splicing of Steel Reinforcing Bars,

8 Ministry of Housing and Urban-Rural Development of China, Beijing, 2010.

9 [35] JGJ 107-2016, Technical specification for mechanical splicing of steel reinforcing bars,

10 Ministry of Housing and Urban-Rural Development of China, Beijing,2016.

11 [36] F. Yoshida, T. Uemori, A model of large-strain cyclic plasticity describing the Bauschinger

12 effect and workhardening stagnation, Int. J. Plasticity. 18(5) (2002) 661-686.

13 [37] A. Giuffrè, Comportamento Del Cemento Armato Per Sollecitazioni Cicliche Di Forte

14 Intensità, Giornale del Genio Civile. 5(1) (1970) 391-408.

[38] M. Menegotto. Method of analysis for cyclically loaded R. C. plane frames including change 16 in geometry and non-elastic behavior of elements under combines normal force and bending. LABSE symposium on resistance and ultimate deformability of structures acted on by well-defined repeated Loads, Final Reports, 1973. [39] A. Gomes, J. Appleton, Nonlinear cyclic stress-strain relationship of reinforcing bars including buckling, Eng. Struct. 19(10) (1997) 822-826. 